\title{
EFFECT OF BIOLACTIN ADMINISTERED PER OS ON SURVIVABILITY AND BODY WEIGHT OF PIGLETS*
}

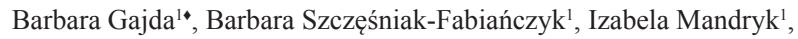 \\ Katarzyna Poniedziałek-Kempny ${ }^{1}$, Florian Ryszka², Barbara Dolińska ${ }^{2}$, Lucyna Leszczyńska², \\ Zdzisław Smorąg ${ }^{1}$ \\ ${ }^{1}$ Department of Biotechnology of Animal Reproduction, National Research Institute \\ of Animal Production, 32-083 Balice n. Kraków, Poland \\ ${ }^{2}$ Pharmaceutical Research and Production Plant (FZNP) "Biochefa”, Kasztanowa 3, \\ 41-205 Sosnowiec, Poland \\ •Corresponding author: barbara.gajda@izoo.krakow.pl
}

\begin{abstract}
Prolactin (PRL) is a protein hormone synthesized in and secreted predominantly by lactotroph cells of the anterior pituitary gland. This hormone has been found to stimulate the immune system in animals. Because prolactin secreted in milk by the mother's body is often insufficient, the administration of exogenous prolactin may significantly contribute to improving the health and growth of piglets. The aim of the study was to determine the dose of prolactin administered to newborn piglets to improve their survivability and growth rate. The study used Biolactin solution, produced on a semi-technical scale by FZNP Biochefa, which was administered per os to newborn piglets at a dose of $0.1,0.5$ and $1.0 \mathrm{mg}$ PRL/kg body weight. $\mathrm{NaCl}$ physiological saline was used as a control. The number of piglets born alive, piglet body weight and mortality from birth to 21 and 28 days of age (weaning) were monitored. The study involved 98 litters (1197 piglets), which were divided into 3 experimental and 3 control groups. The experiment showed a positive effect of exogenous prolactin administered to newborn piglets on reducing their mortality and on increasing their birth to weaning growth rate. A dose of $0.5 \mathrm{mg}$ PRL/kg body weight turned out to be optimal.
\end{abstract}

Key words: pigs, piglets, prolactin, growth rate, mortality

Piglet mortality, which reaches at least a dozen percent on large commercial farms, causes a considerable decrease in reproductive ability of the herd, and thus in overall farm productivity. For this reason, rearing healthy and normally devel-

\footnotetext{
*Author's project of the National Centre for Research and Development, project No. N R12 005710.
} 
oped piglets is among the most important factors determining the profitability of pig production, and weaning the highest possible number of healthy piglets with proper body weight determines the effectiveness of breeding.

Newborn piglets have no antibodies, which means that they are born without natural immunity to environmental pathogens. They only acquire this immunity after ingesting their mother's milk with prolactin, the concentration of which increases considerably in pregnant sows and remains high during milk feeding.

Prolactin (PRL) is a protein hormone synthesized in and secreted predominantly by lactotroph cells of the anterior pituitary gland. These cells are also found in other tissues (such as decidua, placenta, intestine, brain, tissues of the immune system - T and B lymphocytes, monocytes) and in thymic epithelial cells (Michalik and Bartoszewicz, 2002). Prolactin is involved in osmoregulation, body growth and development, regulation of reproductive processes, and carbohydrate and lipid metabolism (Bole-Feysot et al., 1998). Its presence in neurons and glial cells plays a role in energy metabolism by modulating ATPase activity. Prolactin also regulates enzyme activity and hormone secretion (Neill and Nagy, 1994). It stimulates glycogen phosphorylase activity and bile secretion in the liver, and insulin secretion in the pancreas. Prolactin has also been found in endocrine and immune systems, and is thought to play a role in the pathogenesis of autoimmune diseases as an immunomodulatory factor (Drożdż et al., 1998).

The immunological properties of prolactin stimulate the immune system of piglets, which acquire passive immunity in this way. This reduces the risk of acute and chronic infections, most often manifested as diarrhoea. However, prolactin secreted in milk by the mother's body is often insufficient. Based on our earlier studies (Smorąg et al., 2008; Gajda et al., 2011; Gajda et al., 2012), which showed that giving a dose of approx. 0.1 to $1.0 \mathrm{mg}$ prolactin to a piglet immediately after birth had a beneficial effect on rearing performance during the first weeks of life, we attempted to determine the optimum dose of prolactin administered to newborn piglets to improve their survivability and growth rate.

\section{Material and methods}

The study was carried out at the Experimental Station of the National Research Institute of Animal Production in Żerniki Wielkie. Biolactin solution, produced on a semi-technical scale by FZNP Biochefa with different prolactin concentrations $(1.0 \mathrm{mg}, 5.0 \mathrm{mg}$ or $10.0 \mathrm{mg}$ in $10 \mathrm{ml}$ ) was used. The preparation was administered per os immediately after birth to piglets at a dose of $0.1 \mathrm{mg}$ (exp. group I), $0.5 \mathrm{mg}$ (exp. group II) and $1.0 \mathrm{mg}$ (exp. group III) prolactin per kg body weight. Piglets in the control groups (I-III) received $\mathrm{NaCl}$ physiological saline per os. The number of piglets born alive, piglet body weight at birth and on days 21 and 28 (weaning), as well as piglet mortality to 21 and 28 days of age were recorded. The study used 98 litters (1197 piglets), which were divided into 3 experimental and 3 control groups. 
The results were analysed statistically with the T test and the Chi-square test by Statistica, StatSoft Inc. (2011).

\section{Results}

The number of litters, the number of piglets born, and the mean number of piglets per litter in the experimental and control groups are presented in Table 1.

Table 1. Number of litters, number of piglets born alive, and mean number of piglets born per litter in the experimental and control groups

\begin{tabular}{l|c|c|c|c|c|c|c}
\hline \multirow{2}{*}{ Groups } & \multicolumn{2}{c|}{ I } & \multicolumn{2}{c|}{ II } & \multicolumn{2}{c|}{ III } & \multirow{2}{*}{ Total } \\
\cline { 2 - 6 } & experimental & control & experimental & control & experimental & control & 98 \\
\hline $\begin{array}{l}\text { Number of litters } \\
\begin{array}{l}\text { Number of piglets } \\
\text { born alive }\end{array}\end{array}$ & 27 & 18 & 16 & 9 & 19 & 9 & 98 \\
$\begin{array}{l}\text { Mean number of } \\
\text { piglets born alive/ }\end{array}$ & 330 & 224 & 183 & 106 & 235 & 119 & 1197 \\
litter & 12.2 & 12.4 & 11.4 & 11.8 & 12.4 & 13.2 & 12.2 \\
\hline
\end{tabular}

Experimental groups I, II and III - piglets received respectively $0.1 \mathrm{mg}, 0.5 \mathrm{mg}$ or $1.0 \mathrm{mg}$ of prolactin per $\mathrm{kg}$ body weight.

Control groups I, II and III - piglets received $\mathrm{NaCl}$ physiological saline.

In experimental group $\mathrm{I}$, in which piglets received $0.1 \mathrm{mg}$ of prolactin per $\mathrm{kg}$ body weight, the number of live piglets per litter was 12.2, 11.0 and 10.9 at birth and at 21 and 28 days of age, respectively. In the simultaneously reared control group, there were 12.4, 10.3 and 10.1 live piglets at birth and at 21 and 28 days of age, respectively. The mean body weight of the piglets at birth and at 21 and 28 days, the mean daily weight gains in the first three and four weeks of life, and percentage of mortality during the corresponding periods are presented in graphs (Figures $1 \mathrm{a}, \mathrm{b}$ and c).

Piglets that received Biolactin with $0.1 \mathrm{mg}$ prolactin were characterized by slightly higher body weight at birth and at 21 days (Figure $1 \mathrm{a}$ ) in comparison to the piglets in the control group. Daily gains from birth to weaning (day 28) in the control group were about $2.7 \mathrm{~g}$ higher (Figure $1 \mathrm{~b}$ ) in comparison to the piglets receiving Biolactin (all differences statistically non significant). During the entire observation period in the experimental group, percentage mortality was lower (Figure $1 \mathrm{c}$ ) compared to the control group (differences statistically non significant).

In litters from experimental group II, which received $0.5 \mathrm{mg}$ prolactin per $\mathrm{kg}$ body weight, the mean number of live piglets was 11.4 at birth and 10.6 and 10.4 at 21 and 28 days of age, respectively. The corresponding values in the control group were 11.8, 9.4 and 9.3 live pigs. The mean body weight of the piglets at birth and at 21 and 28 days, the mean daily gains in the first three and four weeks of age, and percentage of mortality in the corresponding periods are shown in graphs (Figures $2 \mathrm{a}, \mathrm{b}$ and $\mathrm{c})$. 
a)

匹 $0.1 \mathrm{mg}$ PRL control group

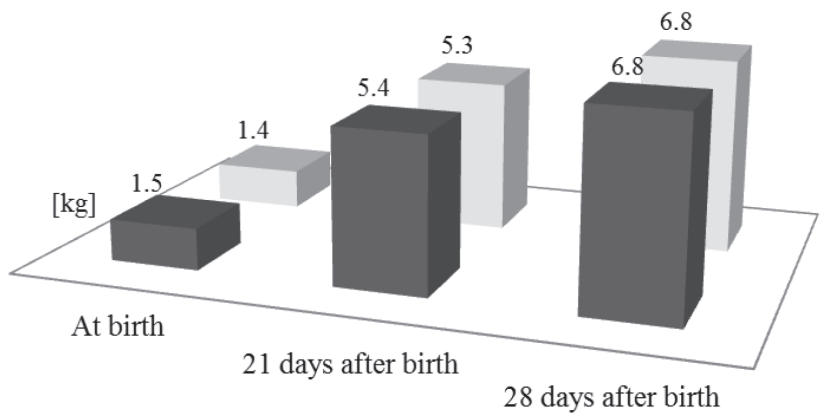

b)

- $0.1 \mathrm{mg}$ PRL control group

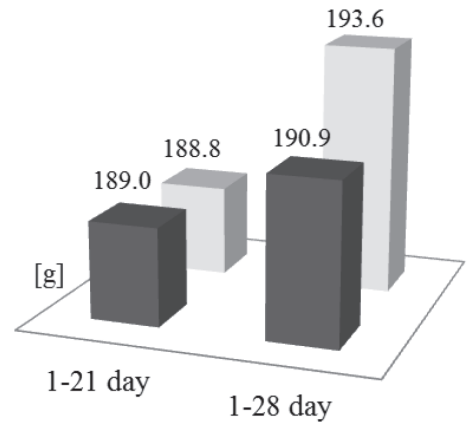

c)

- $0.1 \mathrm{mg}$ PRL control group

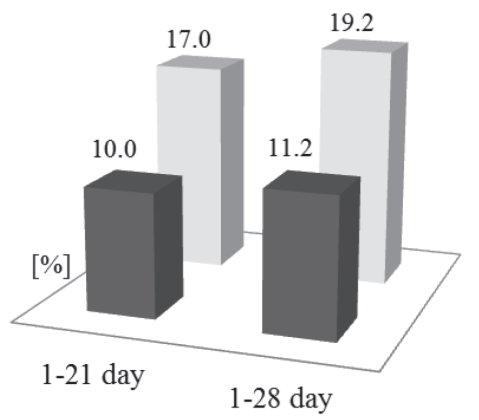

Figures $1 \mathrm{a}, \mathrm{b}$ and $\mathrm{c}$. Mean body weight of piglets (a), mean daily gain (b) and percentage of mortality (c) in experimental group I ( $0.1 \mathrm{mg}$ PRL) and control group

Piglets from this experimental group achieved higher mean body weight by about $0.4 \mathrm{~kg}$ on both day $21(\mathrm{P} \leq 0.05)$ and 28 (differences statistically non significant) in comparison to control group (Figure 2 a). Piglets that received Biolactin had daily gains that were higher $(\mathrm{P} \leq 0.01)$ in comparison to piglets without prolactin (Figure 2 b). The same litters were also characterized by much lower piglet mortality. During the first three weeks, percentage of mortality (Figure $2 \mathrm{c}$ ) in control litters was over twice that in experimental litters $(\mathrm{P} \leq 0.01)$, and during the period from birth to weaning (four weeks) it was over $9 \%$ higher $(\mathrm{P} \leq 0.05)$ than in litters receiving prolactin.

In experimental group III, in which piglets received $1.0 \mathrm{mg}$ prolactin per $\mathrm{kg}$ body weight, there were 12.4, 11.1 and 11.0 live piglets per litter at birth and at 21 and 28 days of age, respectively. The corresponding values in the control group were 13.2, 11.6 and 11.4. The mean body weight of the piglets at birth and at 21 and 28 days, the 
mean daily gains in the first three and four weeks of age, and percentage of mortality in the corresponding periods are shown in graphs (Figures $3 \mathrm{a}, \mathrm{b}$ and $\mathrm{c}$ ).

a)

๑ $0.5 \mathrm{mg}$ PRL control group

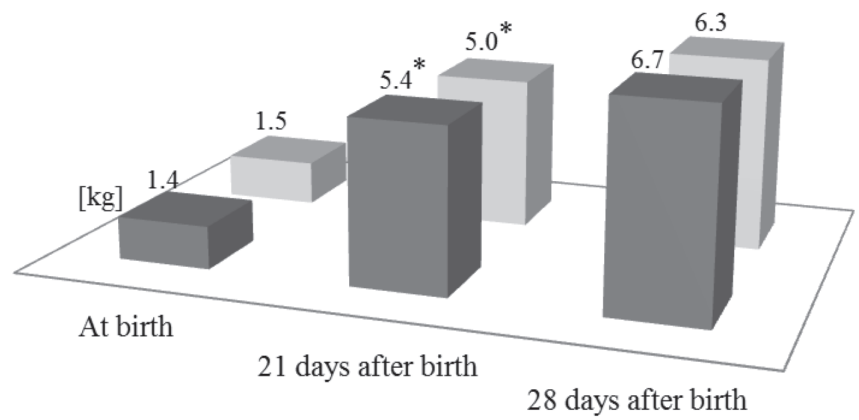

b)

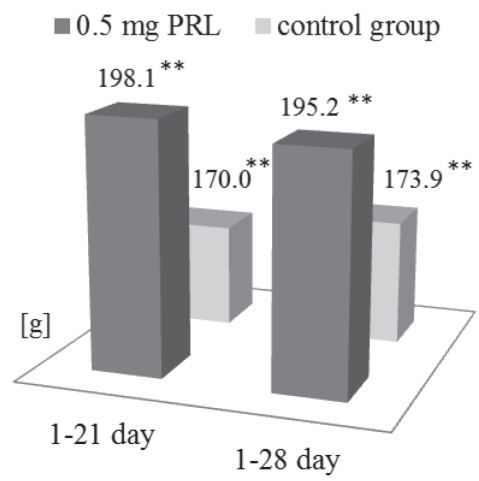

c)

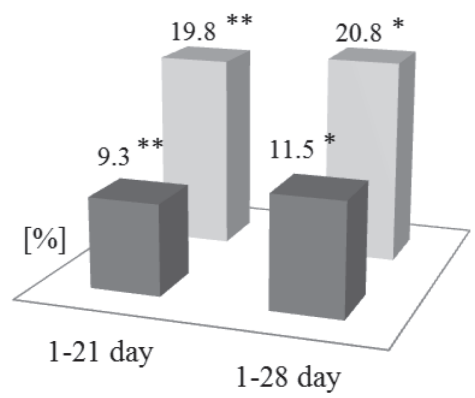

** Statistically significant differences at $\mathrm{P} \leq 0.01$.

* Statistically significant differences at $\mathrm{P} \leq 0.05$.

Figure $2 \mathrm{a}, \mathrm{b}$ and $\mathrm{c}$. Mean body weight of piglets (a), mean daily gain (b) and percentage of mortality (c) in experimental group II ( $0.5 \mathrm{mg}$ PRL) and control group

Piglets that received $1.0 \mathrm{mg}$ of prolactin after birth were characterized by higher body weight at 21 and 28 days (Figure 3 a) (differences statistically non significant) and higher daily gains (Figure $3 \mathrm{~b}$ ) compared to the control piglets. The differences in daily gains over the four weeks were statistically significant $(\mathrm{P} \leq 0.05)$. In the experimental group, percentage of mortality was lower than in control throughout the observation period (Figure $3 \mathrm{c}$ ) but the differences were statistically not significant. 
a)

-1.0 mg PRL control group

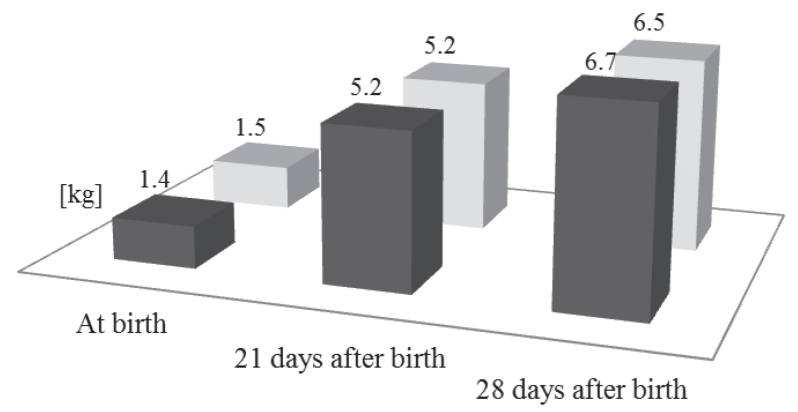

b)

$\square 1.0 \mathrm{mg}$ PRL control group

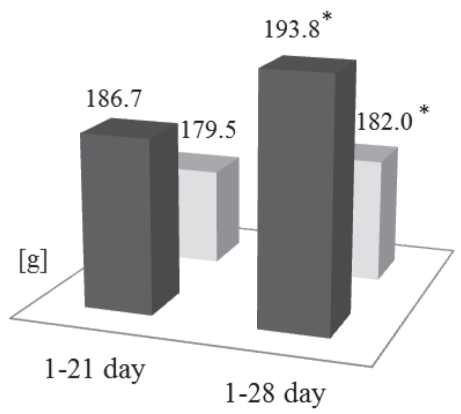

c)

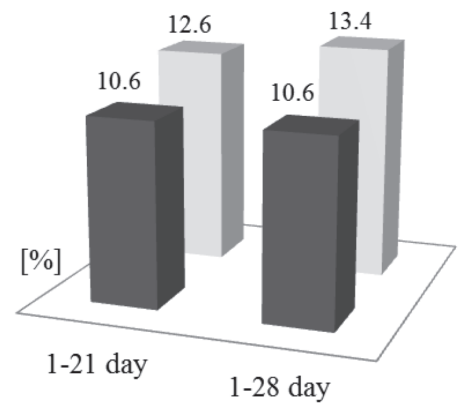

* Statistically significant differences at $\mathrm{P} \leq 0.05$.

Figures $3 \mathrm{a}, \mathrm{b}$ and $\mathrm{c}$. Mean body weight of piglets (a), mean daily gain (b) and percentage of mortality (c) in experimental group III (1.0 mg PRL) and control group

\section{Discussion}

The effectiveness of pig production is among others determined by health and normal development of piglets. The administration of exogenous prolactin may significantly contribute to improving the survivability of piglets, thus increasing the number of weaned piglets and body weight gains. In our experiment lower mortality was found in the group of piglets receiving exogenous prolactin. A decrease of piglet mortality rate may be a consequence of their increased immunity gained as a result of prolactin administration (Michalik and Bartoszewicz, 2002). A very significant mortality rate decrease that reached $10 \%$ in the best experimental case $(0.5 \mathrm{mg}$ of prolactin per kg body weight) has been observed when general piglet mortality at the 
farm was high (approx. 20\%). Such mortality level is above average for pig farms. During periods of lower general mortality, the observed differences have not been that significant.

Piglets supplemented with prolactin had higher daily gains and achieved higher body weight at 21 and 28 days of age in comparison to piglets without prolactin. These results confirmed our earlier pilot study (Smorąg et al., 2008), which demonstrated that giving a dose of 0.1 to $1.0 \mathrm{mg}$ prolactin to newborn piglets had a positive effect on their rearing performance during the first 3 weeks of life. In this experiment only daily gains from birth to weaning (day 28) of the piglets in the control group were about $2.7 \mathrm{~g}$ higher in comparison to the piglets receiving Biolactin with $0.1 \mathrm{mg}$ prolactin. This was probably due to death losses in piglets with low body weight during the fourth week of age.

As a result of the performed experiments we determined the optimum dose of prolactin $(0.5 \mathrm{mg} / \mathrm{kg}$ body weight), the administration of which resulted in highest daily gains of the piglets and lowest mortality. A dose increase up to $1.0 \mathrm{mg}$ per $\mathrm{kg}$ body weight resulted in a certain decrease of its efficiency. This may be considered as the confirmation of a pharmaceutical rule concerning an optimal dosage of a medicine (Heber et al., 1984; Meller et al., 2001).

To date, prolactin has been presented as a solution for sows lacking the milk (Dusza et al., 1991; Przała et al., 1992; Szczęśniak-Fabiańczyk et al., 2002).

The results of our experiment, which demonstrated a positive effect of giving Biolactin to newborn piglets on their survivability and rearing performance to 28 days of age, widen its application scope in pig breeding.

\section{References}

B ole-Feys ot C., G offin V., Edery M., B in art N., Kelly P.A. (1998). Prolactin (PRL) and its receptor: actions, signal transduction pathways and phenotypes observed in PRL, receptor knockout mice. Endocrine Review, 19 (3): 225-284.

D r o ż d ż M., R y s z k a F., P a r d e l a M. (1998). Prolactin (PRL) - a review of current knowledge and new perspectives on clinical use. Med. Sci. Monit. 4 (1): 191-194.

D u s z a L., S o b c z a k J., J a n a B., M u rd z a A., B l u j W. (1991). Application of Biolactin-2 (purified porcine prolactin) in stimulation of lactation in sows (in Polish). Med. Weter., 47 (9): 418-421.

Gajda B., Szczęśniak-Fabiánczyk B., Grad I., Poniedziałek K., Ryszka F., S m or ąg Z., D o liń s k a B., L e s z c z y ń s k a L. (2011). Effect of "Biolactin” administered per os on viability and body weight of piglets. Acta Biochim. Pol., 58 (Suppl. No. 4), p. 147.

Gajda B., Szczęśniak-Fabiańczyk B., Grad I., Poniedziałek K., Ryszka F., S morąg Z., Dolińska B., Leszczyńska L. (2012). Effect of low prolactin dose administered per os on mortality and body weight of piglets. Reprod. Domestic. Anim., 47 (Suppl. 4), p. 574, abstr. 2855.

He be r D., B ha s in S., S te in e r B., S w e r d l o ff R.S. (1984). The stimulatory and down-regulatory effects of a gonadotropin releasing hormone agonist in men. J. Clin. Endocrinol. Metab., 6: 1084-1088.

M e 11 e r W.H., G r a m b s c h P.L., B ing ha m C. (2001). Hypothalamic pituitary gonadal axis dysregulation in depressed women. Psychoneuroendocrinology, 26: 253-259.

Mi c hali k J., B a r to s z e w i c z Z. (2002). Prolactin - a multifunctional, pituitary, peptide hormone. (in Polish). Postępy Biochemii, 48 (4): 296-305. 
N e i 11 J.D., N a g y G.M., (1994). Prolactin secretion and its control. In: E. Knobil and J.D. Neill (eds). The Physiology of Reproduction. Second edition, Raven Press, New York, USA, pp. 1833-1860.

Przała J., Gajęcki M., Przała F., Ryszka F. (1992). Prophylactic application of Biolactin-2 preparation in replacement gilts and the MMA syndrome (in Polish). Med. Weter., 48 (1): 31-33.

S morąg Z., Ryszka F., Dolińska B., Szczęśniak-Fabiańczyk B., Leszczyńs k a L., K o s k a M., K o w a ls k i W. (2008). Effect of prolactin administered per os on body gain and health of piglets. Acta Bioch. Pol., 55 (Suppl. No. 4), p. 133.

Szczęśniak-Fabiańczyk B., Dolińska B., Ryszka F., S morąg Z. (2002). Efficiency of Biolactin administered to primiparous and multiparous sows. Ann. Anim. Sci., 2 (Suppl. No. 2): $173-176$.

Accepted for printing 26 VII 2013 